\title{
Characterization of potential elastase inhibitor-peptides regulated by a molecular switch for wound dressings applications
}

\author{
Sandra Cerqueira Barros ${ }^{\mathrm{a}}$, José Alberto Martinss ${ }^{\mathrm{a}}$, João Carlos Marcos ${ }^{\mathrm{a}}$, Artur Cavaco-Paulo ${ }^{\mathrm{b}, *}$ \\ a Center of Chemistry, University of Minho, Campus de Gualtar, 4710-057 Braga, Portugal \\ b Textile Engineering Department, University of Minho, Campus de Azurém, 4800-058 Guimarães, Portugal
}

\section{A R T I C L E I N F O}

\section{Article history:}

Received 17 May 2011

Received in revised form 27 October 2011

Accepted 31 October 2011

\section{Keywords:}

Elastase

Inhibitor-peptides

Wound dressings

Micro-arrays

Phosphorylation

Luminometry

\begin{abstract}
A B S T R A C T
Elastase plays an important role in wound healing process, degrading damaged tissue and allowing complete tissue recovery. The levels of human neutrophil elastase (HNE) are usually controlled by endogenous inhibitors. However, in the presence of high levels of elastase, like the ones present in chronic wounds, the inhibitors cannot overcome this overproduction and the enzyme starts to degrade the surrounding healthy tissue. In this work we report the development of a molecular switch to control the elastase activity in the exudate of non-healing chronic wounds. A peptide library was generated and screened in a microarray format for protein kinase-mediated phosphorylation. Two peptides were identified as casein kinase I $\delta$ (CKI) substrates: KRCCPDTCGIKCL and its analogous peptide KRMMPDTMGIKML, with cysteine residues replaced by methionine residues. These peptides were studied in solution, both in the phosphorylated and non-phosphorylated forms as potential inhibitors for elastase. The obtained results show that the reversible process of phosphorylation/dephosphorylation results in differential inhibitory activity of the peptides. Thus the reversible process of phosphorylation/dephosphorylation can be used as a kind of molecular switch to control elastase activity. Degradation studies reveal that both the inhibitor-peptides and CKI are degraded by elastase. These results envisage the safe utilisation of these inhibitor-peptides together with CKI in the formulation of wound dressings.
\end{abstract}

(c) 2011 Elsevier Inc. All rights reserved.

\section{Introduction}

Non-healing chronic wounds, such as pressure, venous and diabetic ulcers, are an important and persistent problem in dermatology [1]. In healing acute wounds such as injuries or surgical procedures (fluids from ablation of seborrheic warts, for example) the levels of protein-degrading enzymes are low whereas in chronic non-healing wounds the exudates (from ulcers fluids, for example) contain high levels of proteases, such as elastase and matrix metalloproteinases (MMPs) [2-4]. Elevated levels of elastase (36-54 munits/mL wound fluid) [5] degrade cytokine growth factors, fibronectin and reduce the endogenous levels of protease

Abbreviations: SLPI, secretory leukocyte protease inhibitor; ECP, eosinophil cationic protein; SP-D, surfactant protein D; ESI, elastase specific inhibitor; HNE, human neutrophil elastase; PPE, porcine pancreatic elastase; MBP, myelin basic protein; CKI $\delta$, casein kinase I delta isoform; Ser(P), phoshoseryl residue; Thr(P), phosphothreonyl residue; Xaa, any given aminoacid; HTS, high throughput screen; RLUs, relative light units; $\mathrm{EC}_{50}$, enzyme concentration at $50 \%$ of signal; Peptide 4, Pep4; Peptide 4, KRCCPDTCGIKCL; Peptide 4 Modified, Pep4M; Peptide 4 Modified, KRMMPDTMGIKML; p-NA, p-nitroaniline; MS, mass spectrometry; SDS-PAGE, sodium dodecyl sulfate polyacrylamide gel electrophoresis; SD, standard deviation.

* Corresponding author. Tel.: +351253 510271; fax: +351 253510293.

E-mail address: artur@det.uminho.pt (A. Cavaco-Paulo). inhibitors. In acute wounds, minimal levels of elastase $(245.9 \mathrm{ng} / \mathrm{mg}$ protein) [4] and matrix metalloproteinases (1.6 ng/mg protein MMP-2 and $0.2 \mathrm{ng} / \mathrm{mg}$ protein MMP-13) [4] are required for an appropriate healing process. The elastase levels are controlled by endogenous inhibitors such as alpha-1 proteinase inhibitor ( $\alpha 1-\mathrm{PI})$, secretory leukocyte protease inhibitor (SLPI) and Elafin [6].

The levels of proteases in chronic wounds may be reduced to levels similar to those found in acute wounds using bioactive wound dressings composed of peptide $[7,8]$ and carbohydrate derivatized cotton [9], ionically derivatized dressings of cotton [10,11] and hydrogel polymers [12]. Controlled release of protease inhibitors from wound dressings and biomaterials, such as collagen, alginate, chitosan, carboxymethylcellulose, hydrogel polymers, hydrocolloids and polyurethane $[13,14]$ have also been used to reduce the protease burden on chronic wounds. Sequestration of elastase from the wound environment $[11,12,15]$ or the release of elastase inhibitors to the wound medium $[5,16]$, are two plausible approaches to control elastase levels in wound exudates. The present work relies on the second concept as a methodology to control the imbalance between proteases and their inhibitors. The inhibitor-peptides studied herein were selected from the endogenous elastase inhibitors SLPI and Elafin and from two other endogenous proteins, eosinophil cationic protein (ECP) and surfactant protein D (SP-D). Elafin and SLPI have high cysteine content, 
8 and 16 residues respectively, with the correct pairing of disulfide bridges being crucial for elastase inhibition [17-19]. Elafin is a potent inhibitor of both human neutrophil elastase (HNE) and porcine pancreatic elastase (PPE) [18-20], whereas SLPI is a strong HNE inhibitor but a weak PPE inhibitor [18-20]. SLPI and Elafin have multiple biological functions: anti-bacterial, anti-fungal, anti-viral, anti-inflammatory and immune-modulatory functions [20-22]. Eosinophil cationic protein is a potent stimulator of mucus secretions by airways epithelial cells [23] acting as a host defence protein due to its bactericidal, helminthotoxic and antiviral activities [24-26]. Furthermore, ECP displays tissue-healing properties regulating fibroblast activity and enhancing collagen release [23,27]. Surfactant protein D (SP-D), originally described as a collagenous glycoprotein [28], belongs to the collectin family of proteins, named for their $\mathrm{N}$-terminal collagen region and $\mathrm{C}$-terminal lectin domain. SP-D is a large hydrophilic molecule with host defence and immune regulatory functions [29-31]: viral neutralization, clearance of bacteria, fungi and apoptotic and necrotic cells, down regulation of allergic reaction and resolution of inflammation [31].

Synthetic protease inhibitors are typically used for protease inhibition. Continuous release of (non-degradable) inhibitors from wound dressings results, over time, in steady concentration buildup in wounds, lowering protease activity levels below those desirable for healing. In vivo, the activity of endogenous proteases is controlled by small protein molecules (inhibitors), known as anti-proteases. A dynamic state of inhibition is achieved by regulating the relative rates of inhibitor synthesis and protease-mediated inhibitor degradation.

We envisage that steady-state low levels of elastase activity in chronic wounds can be achieved by sustained release of (degradable) inhibitor-peptides from wound dressings, coupled to elastase-mediated hydrolysis (deactivation). In addition, if the phosphorylated form of the inhibitor-peptides inhibit elastase to a less extent than the non-phosphorylated form, than protein kinase-mediated phosphorylation reaction, can be seen as a $(0-1)$ molecular switch to fine tune elastase activity.

In the current work we give the first steps towards the proof-ofconcept of this proposal: (i) a peptide library was designed using short peptide sequences derived from the endogenous proteins SLPI, Elafin, ECP and SP-D; (ii) all library members contain a central phosphorylable residue, Ser, Thr or Tyr; (iii) a library of 49 peptide sequences was screened in microarray format for phosphorylable peptides; (iv) the most robust hit identified in the microarray assay, Pep4, was selected for further studies; (v) the phosphorylation of Pep4 and its analogue Pep4M with casein kinase I $\delta$ (CKI) was studied in solution; (vi) the inhibition of elastase by Pep4, Pep4M and their phosphorylated forms was evaluated in solution; (vii) the degradation of Pep4, Pep4M and CKI by elastase was studied in solution by mass spectrometry (MS) and SDS-PAGE electrophoresis, respectively.

\section{Materials and methods}

\subsection{Reagent}

The microarrays and the peptides KRCCPDTCGIKCL (peptide 4 - Pep4) and KRMMPDTMGIKML (peptide 4 modified - Pep4M) were custom-made by JPT Peptide Technologies GmbH (Berlin, Germany). Except where otherwise stated, all reagents were purchased from Sigma Co (St. Louis, MO, USA). Casein kinase I (C4455), Adenosine 5'-triphosphate disodium salt (ATP, A2383) and all reagents used to prepare the buffer solutions employed in the microarray assays, were used as supplied. The microarrays chips were sealed with disposable incubation chambers (AB-0630, $300 \mu \mathrm{L}, 19 \times 60 \mathrm{~mm}$, frames and coverslips, ABgene, Epsom, UK) The blocking reagent (cat $n^{\circ} 11096176001$ ) used in the preparation of the blocking buffer was acquired at Roche Diagnostics GMbH (Basel, $\mathrm{CH}$ ). The microarray stain and destain were performed using the Pro-Q diamond phosphoprotein ge stain (P33301) and Pro-Q diamond destain solution (P33310) from Molecular Probes (Eugene, OR, USA).
The protein kinase assay in solution was performed using the PKLight ${ }^{R}$ High Throughput Screen Protein Kinase assay Kit (LT07-500), from Cambrex (East Rutherford, NY, USA), in a 96-well format (F96 NUNC, Rochester, NY, USA). This assay kit comprises ATP detection reagent (LT27-200), reconstitution buffer A (LT27-202) and B (LT27-207) and kinase stop solution (LT27-228)

Porcine pancreatic elastase (E1250), chromogenic substrate $N$-succinyl-Ala-AlaAla-p-nitroanilide (S4760) and the non-peptide PPE inhibitor Elastatinal (BML-PI103, Enzo Life Sciences, Farmingdale, NY, USA) were used as supplied.

SDS-PAGE reagents: acrylamide/bisacrylamide solution (37.5:1) at $40 \%$ (1610148), TEMED ( $N, N, N^{\prime}, N^{\prime}$-tetra-methyl-ethylenediamine, 161-0800) and APS (Ammonium Persulfate, 161-0700) were purchased to Bio-Rad Laboratories (Hercules, CA, USA). A broad range protein marker (New England BioLabs, Ipswich, USA P7702S) was used in the electrophoresis assay. All reagents used were of analytical grade and all aqueous solutions were prepared in deionized water and stored at $4{ }^{\circ} \mathrm{C}$.

\subsection{Methods}

\subsubsection{On-chip protein kinase phosphorylation}

Jerini phosphosite detector peptide arrays (Jerini Peptide Technologies, GmbH, Berlin, Germany) were used to identify potential phosphorylation sites within a library of forty-nine peptide sequences, derived from the endogenous proteins SLPI, Elafin, ECP and SP-D. Eight controls (Histone 1, 2, 3 and 4, myelin basic protein (MBP), alpha- and beta-casein and Tau protein) were also incorporated into the microarray format. The controls were spotted on the microarray in the four limits of each subarray (three subarrays per array - triplicates), serving simultaneously as positive controls and as landmarks for the identification of phosphorylation signals [32]. 13-Mers L-peptides were generated around central serine, threonine or tyrosine residues in order to improve accessibility to the phosphor-acceptor site. The phosphorylation on-chip was performed according to the PhosphoSiteDetector Protocol, supplied by the manufacturer. Briefly: peptide arrays were sealed with Gene-Frame ${ }^{\mathrm{TM}}$ incubation chambers (AB 0630, Abegene, Epsom, UK), the chambers were filled with $330 \mu \mathrm{L}$ of general kinase buffer (50 mM HEPES - $\mathrm{NaOH}, \mathrm{pH} 7.5$, $5 \mathrm{mM} \mathrm{MgCl}_{2}, 5 \mathrm{mM} \mathrm{MnCl}, 3 \mu \mathrm{M} \mathrm{Na}_{3} \mathrm{VO}_{4}, 1 \mathrm{mM}$ DTT and $1 \mu \mathrm{M}$ ATP), casein kinase I $\delta$ ( 10 units $/ \mathrm{mL}, 8.56 \mu \mathrm{L})$ and ATP $(1 \mathrm{mM}, 33 \mu \mathrm{L})$. After $6 \mathrm{~h}$ of incubation at $35^{\circ} \mathrm{C}$, in a incubator shaker (Infors HT - Minitron, Bottmingen, Switzerland), the incubation chambers were removed from the slides and the microarrays were washed five times, for $5 \mathrm{~min}$, with TBS buffer ( $50 \mathrm{mM}$ Tris- $\mathrm{HCl}$, pH 8.0, $137 \mathrm{mM} \mathrm{NaCl}$ and $2.7 \mathrm{mM}$ $\mathrm{KCl}$ ). Next, the chips were incubated with the blocking solution (blocking reagent and $100 \mathrm{mM}$ maleic acid buffer, $\mathrm{pH} 7.5,150 \mathrm{mM} \mathrm{NaCl}$ ) for $1 \mathrm{~h}$ at $25^{\circ} \mathrm{C}$, rinsed with TBS buffer (five times for $5 \mathrm{~min}$ ) and then dried with airflow. The use of blocking buffer after protein kinase incubation avoids unspecific binding of the phosphor-specific stain, which is applied in last step of this experimental procedure.

To detect the phosphopeptides on the microarrays (Fig. 1), a fluorescence phosphosensor dye - Pro-Q diamond stain (excitation/emission: 555/580 nm, respectively) was used. The microarrays were incubated with the stain for $60 \mathrm{~min}$ and then rinsed three times with destain solution, for a period of $30 \mathrm{~min}$. This was followed by a final wash with ultra-pure water before drying in a nitrogen stream and analysing in a microarray scanner (Agilent and QuantArray).

\subsubsection{Protein kinase phosphorylation in solution}

The enzymatic activity of casein kinase I $\delta$ (CKI) was measured using the PKLight ${ }^{R}$ HTS Protein Kinase assay Kit, from Cambrex (East Rutherford, NY, USA). The protein kinase activity measurements were performed following the manufacturer procedures. The kinase activity was measured in 96-well, white NUNC micro-plates using a total volume of $20 \mu \mathrm{L}$ per well. Casein kinase I $\delta$ was serially diluted in general kinase buffer, directly on the 96-well microplates, to give activities ranging from 3.75 to $1.83 \times 10^{-3}$ units per well. Next, a mixture of substrate ( $8 \mu \mathrm{M}$ Pep4 or Pep4M) and ATP ( 6 and $1 \mu \mathrm{M}$ for Pep4 and Pep4M, respectively), diluted in general kinase buffer was added to all wells, including the negative controls (without casein kinase I $\delta$ ). The reaction mixture was incubated at $25^{\circ} \mathrm{C}$ for $30 \mathrm{~min}$, before adding $5 \mu \mathrm{L}$ of kinase stop solution. The amount of ATP remaining was determined by adding $10 \mu \mathrm{L}$ of ATP detection reagent to each well and incubating for $10 \mathrm{~min}$ at $25^{\circ} \mathrm{C}$ (optimal temperature for the luciferase enzyme). The 96 well-plates were read at $560 \mathrm{~nm}$ on a BioTek, Synergy ${ }^{\mathrm{TM}}$ HT (Winooski, VT, USA), in luminescence mode (Fig. 2).

\subsubsection{Elastase activity measurements}

The activity of porcine pancreatic elastase was assayed with the chromogenic substrate $\mathrm{N}$-succinyl-Ala-Ala-Ala- $\mathrm{p}$-nitroanilide [33], in accordance with the protocol supplied by the PPE manufacturer. The $p$-nitroanilide released was analysed in $1 \mathrm{~mL}$ quartz cells and monitored by recording the absorbance at $410 \mathrm{~nm}$ with a UV-vis Shimadzu spectrophotometer (UV-2501PC, Kyoto, Japan). Substrate concentration and enzyme activity of $4.4 \mathrm{mM}$ and 0.3 units $/ \mathrm{mL}$, respectively, were used in the assay. The enzyme was pre-incubated at $25^{\circ} \mathrm{C}$ with the inhibitor for $5 \mathrm{~min}$ before adding the substrate. The enzyme assays were conducted at $25^{\circ} \mathrm{C}$ in $100 \mathrm{mM}$ Tris- $\mathrm{HCl}$ buffer, $\mathrm{pH}$ 8.0. The hydrolysis rates of $N$-succinyl-(Ala) ${ }_{3}-\mathrm{pNA}$ by PPE were acquired in the presence of inhibitors (Pep4, Pep4M) in concentrations ranging from 1 to $64 \mu \mathrm{M}$ (Fig. 3). The non-peptide (non-hydrolysable) inhibitor elastatinal was used as a control and assayed in the same conditions as the peptides. An assay was also performed using the inhibitor-peptides concentrations that decreased mostly the elastase activity, both in the phosphorylated and non-phosphorylated 


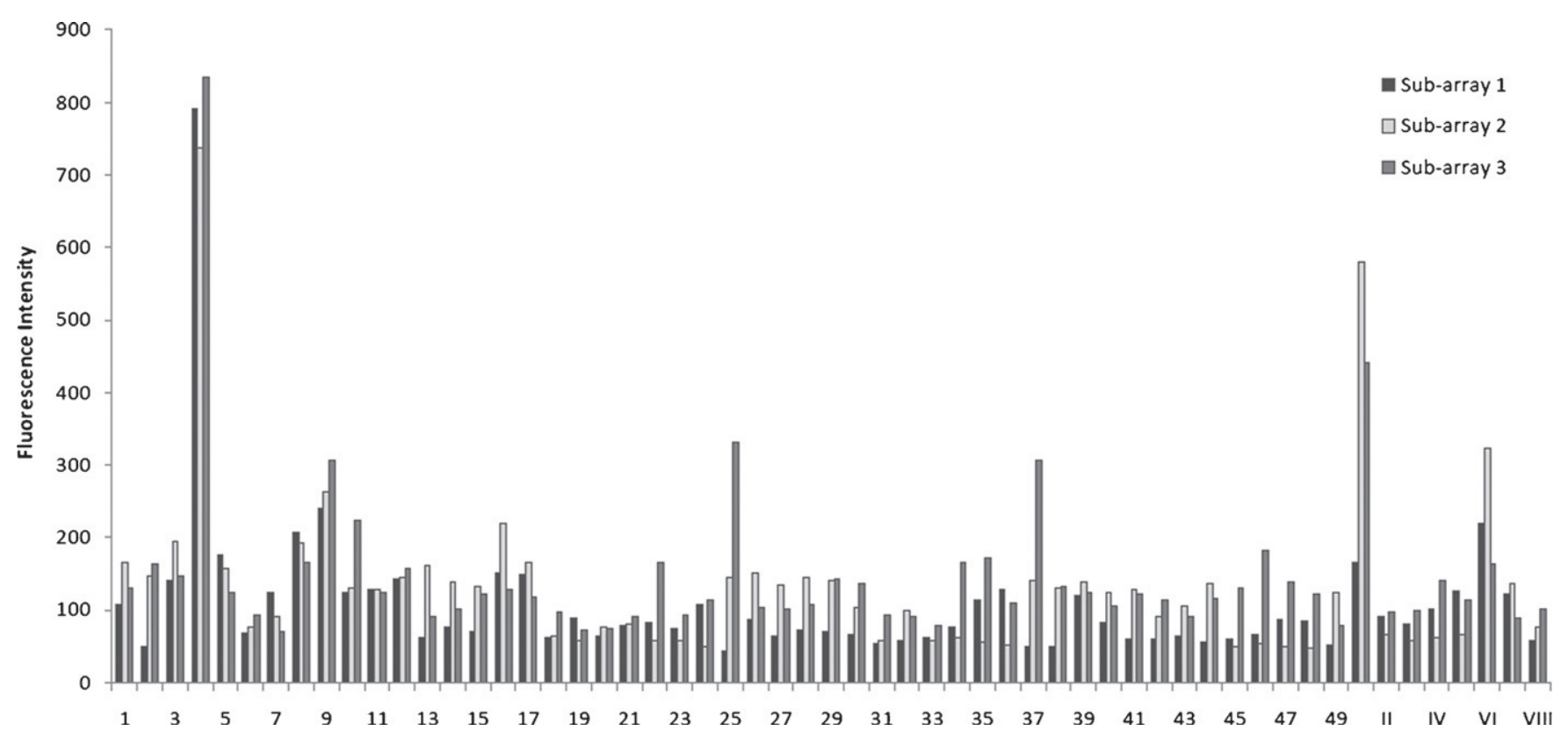

Fig. 1. Microarray screening of the peptide library (peptide 1-49) and protein controls (I-IV - Histone 1, 2, 3 and 4, V - myelin basic protein (MBP), VI and VII - alpha- and beta-casein and VIII - Tau protein), for phosphopeptides after phosphorylation with casein kinase I $\delta$, in triplicate. The slides were probed with a fluorescent phosphosensor (Pro-Q diamond phosphoprotein gel stain) and detected in a microarray scanner (excitation/emission: 555/580 nm, respectively).

form (Fig. 4). The optimized phosphorylation conditions found for the PKLight assay (Fig. 2) were adapted to phosphorylate the peptides in solution. The temperature and incubation time were replaced by that used in the phosphorylation of the peptides in the microarray format $\left(6 \mathrm{~h}\right.$ at $\left.35^{\circ} \mathrm{C}\right)$. The control CKI + ATP was treated in the same conditions as the peptide samples.

2.2.4. Elastase degradation of inhibitor peptides Pep4 and Pep4M - mass analysis Mass spectra of the inhibitors (Pep4, Pep4M and Elastatinal) were acquired on a Thermo Electron Corporation instrument (Waltham, MA, USA), model Finnigan LXQ using electrospray ionization (ESI) in the positive mode. Samples were prepared in a mixture $20 \%$ methanol $/ 80 \%$ buffer solution. A total volume of $200 \mu \mathrm{L}$ was directly injected into the ionization chamber - direct introduction method. Inhibitor samples (data not shown) and mixtures of inhibitor $(0.5 \mathrm{mM})$ : elastase $(0.3$ units $/ \mathrm{mL})$, in a proportion 3:1 (v/v) (Table 2 and Fig. 5), were analysed after different incubation periods $(0,5,15,30,45,60,90$ and $120 \mathrm{~min})$ at $25^{\circ} \mathrm{C}$.

\subsubsection{Elastase degradation of casein kinase - SDS-PAGE electrophoresis}

Sodium dodecyl sulfate-polyacrylamide gel electrophoresis (SDS-PAGE) [34] was used to evaluate the degradation of casein kinase I $\delta$ by elastase. The SDS-PAGE assay was perform as described by Laemmli [34] and in accordance to the Bio-Rad

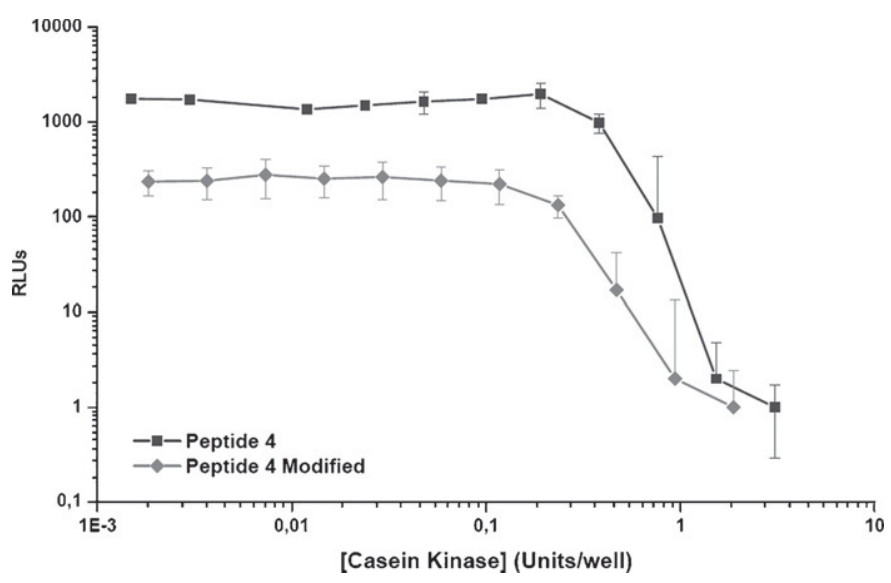

Fig. 2. Casein kinase $I \delta$ titration curve using $3.75-1.83 \times 10^{-3}$ units of $\mathrm{CK}$ per reaction to phosphorylate: $4 \mu \mathrm{M}$ of Pep4, in the presence of $3 \mu \mathrm{M}$ of ATP ( $\mathbf{\square})$ and $4 \mu \mathrm{M}$ of Pep4M, in the presence of $0.5 \mu \mathrm{M}$ of ATP $(\checkmark)$. Each data point represents the average $\pm \operatorname{SD}(n=3)$. manufacturer protocols. Samples were analysed using a $4 \%$ stacking gel followed by a $10 \%$ separating gel, under denaturing conditions. Gels were stained in Coomassie blue R solution (overnight) and destained with methanol/acetic acid (40\%/7\% and $5 \% / 7 \%$ ) solutions. Afterwards, the gels were enclosed in sheets of cellophane membrane and dried in a gel dryer (model 563, Bio-Rad, Hercules, CA, USA) during 60 min at $80^{\circ} \mathrm{C}$, under vacuum conditions.

Samples of casein kinase I $\delta(0.1-0.4$ units $/ \mu \mathrm{L})$ and elastase $(0.005-0.01$ units $/ \mu \mathrm{L})$ with different concentrations were analysed by SDS-PAGE in order to determine the detection limit of the method (data not shown). The optimal concentrations of elastase and casein kinase $I \delta, 0.005$ and 0.2 units/ $\mu \mathrm{L}$, respectively, were used to prepare a mixture of the two proteins. The reaction mixture was incubated for $60 \mathrm{~min}$. During this period several aliquots were removed $(0,5,10,20,30$ and $60 \mathrm{~min})$ and immediately frozen for further analysis. The thawed samples were analysed by SDS-PAGE along with protein markers (Fig. 6).

\subsubsection{Statistical analysis}

Statistical analyses (standard deviation) were performed using the Microsoft Office Excel 2010. Prior to statistical treatments, data validation was performed using Dixon's Q-test. A confidence level of 95\% was used as the cut off level.

\section{Results and discussion}

\subsection{Peptide library design and on-chip phosphorylation}

A peptide library was designed using short peptide sequences (13 mer) derived from the primary sequence of the endogenous proteins SLPI, Elafin, ECP and SP-D. Phosphorylable residues, Ser, Thr and Tyr, within the proteins primary structure were selected as anchors and extended in both directions with six aminoacid residues. As such, all library members contain a central phosphorylable residue (residue seven), Ser, Thr or Tyr, flanked by six amino-acid residues. For incorporation onto the microarrays, the peptides were $\mathrm{N}$-functionalized with a hydrophilic linker, 1-amino-4,7,10-trioxa-13-tridecanamine, bearing terminal aminooxyacetyl moieties for chemoselective immobilization onto aldehyde-functionalized glass slides. It is, thus, reasonable to assume that the peptides and in particular the central phosphorylable residues are accessible to enzymes. The peptide library (Table 1) was screened for potential substrates for protein kinases, by means of the microarray technology. The peptide origin, its sequence and the phosphor-aminoacids are highlighted in Table 1. 


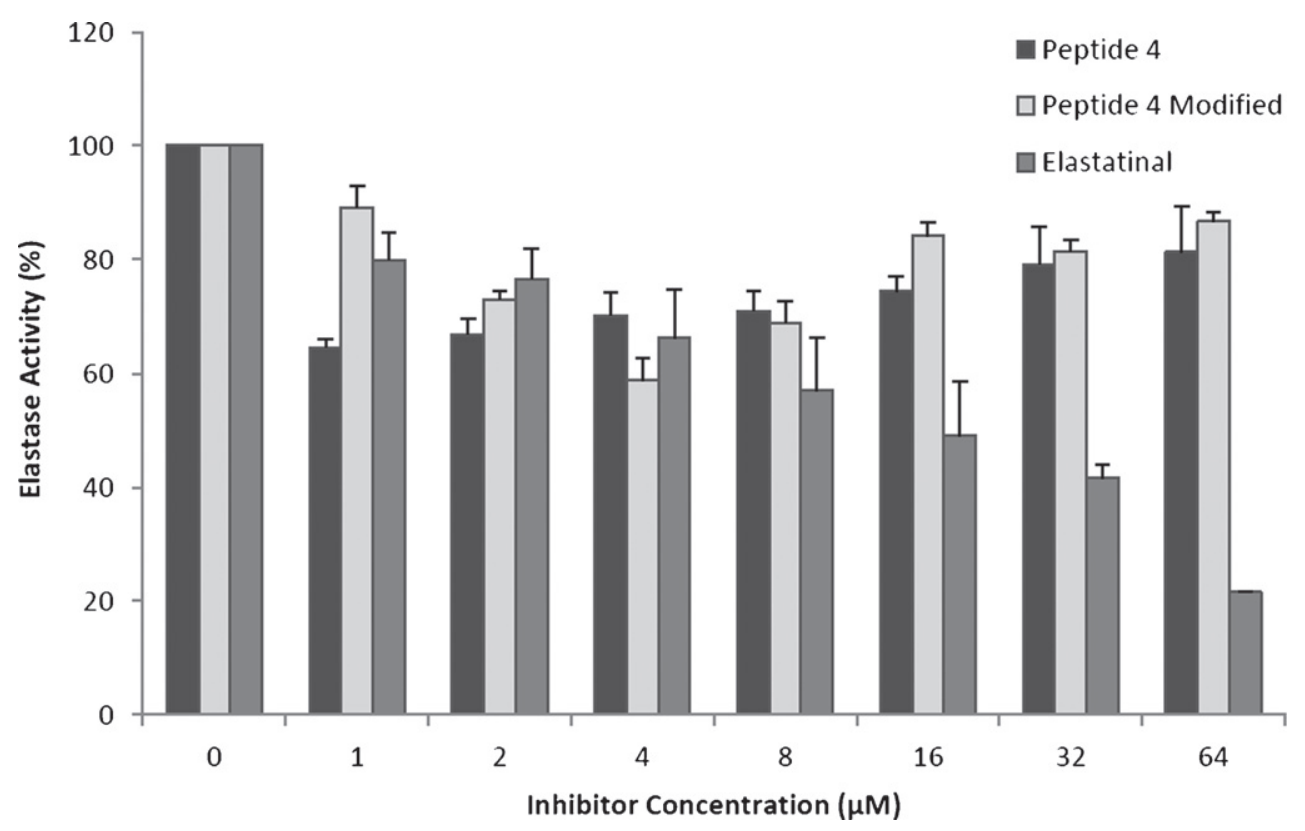

Fig. 3. Porcine pancreatic elastase activity assay in the presence of three inhibitors: Pep $4(\boldsymbol{\square})$; Pep4M ( $\square$ ) and elastatinal ( $\square$ ), in concentrations ranging $1-64 \mu \mathrm{M}$. The enzymatic assay was performed using 0.3 units $/ \mathrm{mL}$ of PPE and $4.4 \mathrm{mM}$ of substrate, $N$-succinyl-Ala-Ala-Ala- $p$-nitroanilide, in a $100 \mathrm{mM}$ Tris-HCl, pH 8.0 buffer medium. The $p$-nitroanilide release was monitored in a UV-vis spectrometer, at $410 \mathrm{~nm}$. Data shown are the mean $\pm \mathrm{SD}$ of triplicate determinations.

The database NetPhos 2.0 server [35] was used to screen the peptide library for potential phosphorylation sites (Table 1). Nineteen peptides, out of the 49 library members, were predicted as bearing potential sites for phosphorylation, although only 12 displayed a high degree of confidence score (threshold higher than 0.90).

The peptide library, immobilized on glass slides together with eight full-length proteins, was initially assayed with casein kinase I $\delta$ and other protein kinases, such as protein kinase A and protein kinase C. Reliable results were obtained only with CKI and presented thereafter. The fluorescence intensity of each spot on the microarray was normalized by subtracting background's intensity. The Peptide KRCCPDTCGIKCL (entry 4 in Table 1, thereafter

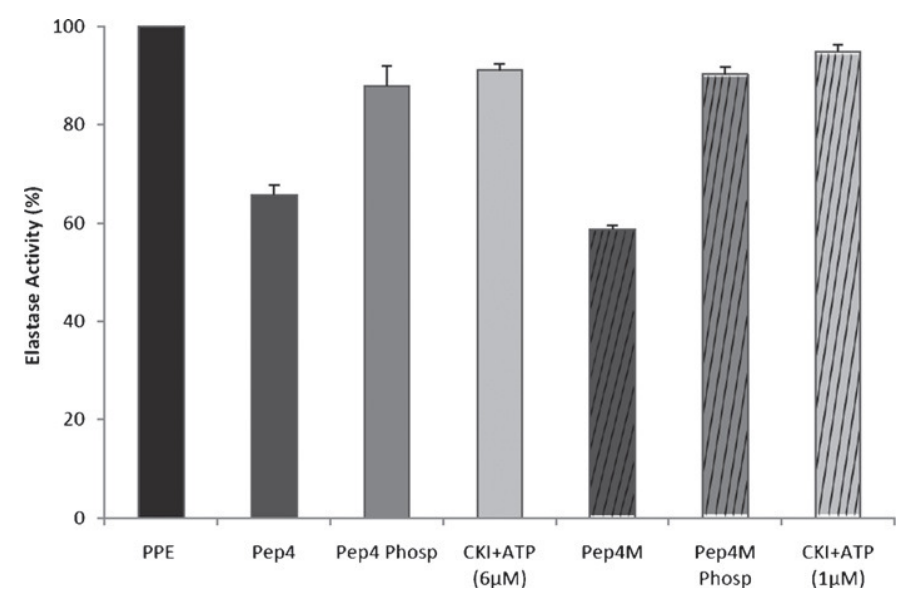

Fig. 4. Porcine pancreatic elastase (PPE) activity in the presence of nonphosphorylated inhibitors Pep4 ( $\square$ ) and Pep4M ( $\square$ dashed), and phosphorylated inhibitors Pep4 Phosp ( $\square$ ) and Pep4M Phosp ( $\square$ dashed). Concentrations of the Pep4 and Pep4M inhibitors in the assay were $1 \mu \mathrm{M}$ and $4 \mu \mathrm{M}$, respectively. Controls in the absence of inhibitors PPE ( $\square$ ) and in the presence of casein kinase I $\delta$ and ATP, CKI + ATP ( $\square$ and $\mathbf{\square}$ dashed) are also shown. Two different assays are shown for the later control corresponding to the conditions for Pep4 phosphorylation (17.8 units of CKI and $6 \mu \mathrm{M}$ of ATP) ( $\square$ ) and Pep4M phosphorylation (12.6 units of CKI and $1 \mu \mathrm{M}$ of ATP) ( $\square$ dashed). The experimental conditions are the same as used in Fig. 3. The data shown are the average of three independent measurements. designated Peptide 4, and abbreviated Pep4) was the only peptide found to be reproducibly phosphorylated by CKI in the three sub-arrays. Peptide GKCPVTYGQCLML (entry 9), RCPHNRTLNNCHR (entry 25) and GESLVYSNWAPGE (entry 37) and the protein controls Histone I, Histone II and $\alpha$-Casein, were also phosphorylated although not reproducibly in the three sub-arrays. Interestingly, out of the 4 hits only peptide GESLVYSNWAPGE (entry 37) was predicted by NetPhos 2.0 as a potential substrate for phosphorylation. Peptide KRCCPDTCGIKCL(Pep4), the most reliable hit found, was not identified by the NetPhos server as a potential substrate for protein kinases. Accessibility to the phospho-site or different conformations on the immobilized state might explain the discrepancies observed. Casein kinase I belongs to a family of Ser/Thr protein kinases, characterized by its preference for acidic protein substrates, such as casein and phosvitin, containing acidic residues (Glu or Asp) in the vicinity of the phosphorylation sites [36]. Prior substrate phosphorylation was identified as critical for CKI phosphorylation [37]. A consensus sequence with

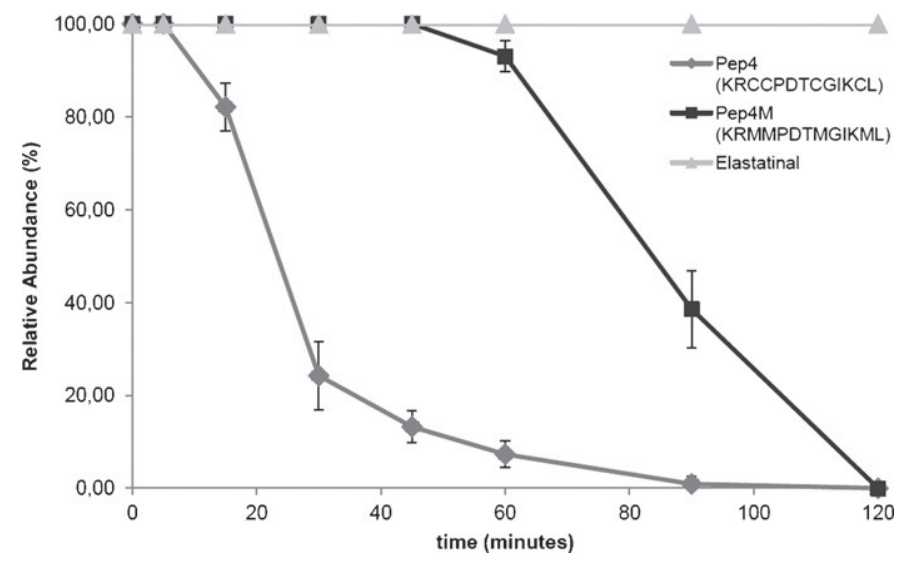

Fig. 5. MS study on the degradation of the inhibitors Pep4 $(\bullet), \operatorname{Pep} 4 \mathrm{M}(\boldsymbol{\square})$ and Elastatinal $(\triangle)(0.5 \mathrm{mM})$ by PPE $(0.3$ units $/ \mathrm{mL})$, in a ratio $3: 1(\mathrm{v} / \mathrm{v})$, during an incubation period of $120 \mathrm{~min}$. Data points represent the mean of three assays $\pm \mathrm{SD}$. 


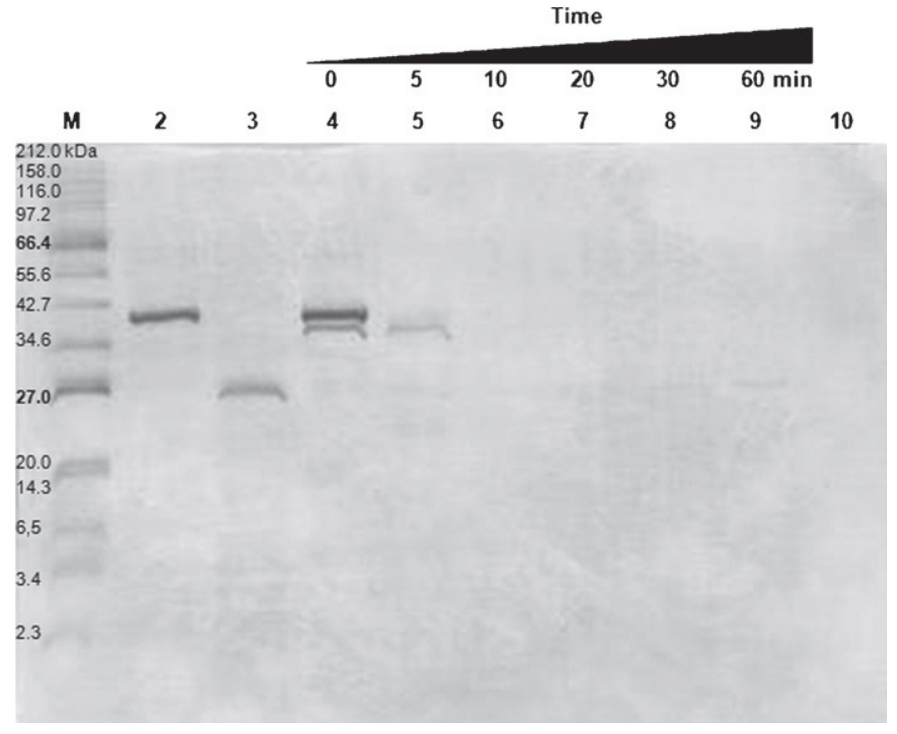

Fig. 6. Electrophoresis (SDS-PAGE) study on the degradation of casein kinase I $\delta$ $(0.2$ units $/ \mu \mathrm{L})$ by PPE $(0.005$ units $/ \mu \mathrm{L})$, in a ratio $40: 1(\mathrm{v} / \mathrm{v})$. The SDS-PAGE gel was

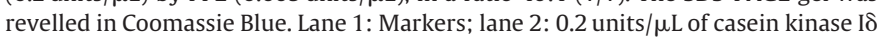
(41.8 kDa); lane 3: 0.005 units $/ \mu \mathrm{L}$ of elastase (29.9 kDa) and lanes 4-9: mixture of elastase and casein kinase $I \delta$ in a proportion 1:40.

N-terminal pre-phosphorylated residues, Ser(P)/Thr(P)-Xaa-XaaSer/Thr (Xaa - any aminoacid), is not an absolute requirement for efficient and high-affinity phosphorylation by CKI as long as multiple acidic residues are present on the $\mathrm{N}$-terminal side of the phosphor-acceptor aminoacid. Such behaviour supports the concept that CKI could act as a primary protein kinase [37] and not only as a secondary protein kinase (requiring previous substrate phosphorylation) [38]. Nonetheless, phosphoserine/phosphothreonine determinants are superior to carboxylic amino acids, as specific determinants for CKI [38]. Despite not containing the consensus sequence, the acidic aspartic acid residue (D) on the N-terminal side of the phosphor-acceptor residue rends Pep4 an appropriate substrate for CKI. In this assay, casein kinase I $\delta$ behaves as a primary protein kinase [37].

\subsection{Phosphorylation of the inhibitor peptides in solution}

The most reliable hit identified in the microarray assay as substrate for casein kinase Iס, Pep4 (KRCCPDTCGIKCL), was purchased from JPT Technologies. An analogous peptide, in which the 4 cysteine residues were replaced by methionine residues (KRMMPDTMGIKML), thereafter designated Pep4M, was also purchased. This peptide was used as control to exclude aggregation or some other form of oligomerization of Pep4 in solution, resulting from intramolecular and/or intermolecular disulfide bridges. The CKI-mediated phosphorylation of both peptides in solution was assessed using the PKLight HTS in vitro assay (Fig. 2) [39]. Different concentrations of peptide ( 4 and $8 \mu \mathrm{M})$ and $\operatorname{ATP}(1,2,6$ or $8 \mu \mathrm{M})$ and incubation periods $(15,30$ or $50 \mathrm{~min})$ were tested for optimizing phosphorylation reactions (data not shown). The best results were obtained with 30 min of incubation with CKI, $8 \mu \mathrm{M}$ concentration of both peptides, together with 6 and $1 \mu \mathrm{M}$ concentration of ATP for Pep4 and Pep4M, respectively. This assay validates the microarray result confirming that Pep4 is a substrate for CKI-mediated phosphorylation. Mutated (cysteine $\rightarrow$ methionine) peptide Pep4M, is also a substrate for $\mathrm{CKI}$. The values of $\mathrm{EC}_{50}$ (the concentration of enzyme that gives $50 \%$ of maximum peptide phosphorylation [40]) were determined from CKI titration curves using 7.94 and 3.16 units of casein kinase $I \delta$, for Pep4 and Pep4M, respectively.

\subsection{Elastase activity measurements}

The inhibition of porcine pancreatic elastase by peptides Pep4 and Pep4M was assayed in vitro with the chromogenic substrate $N$ succinyl-Ala $3-p N A$ (Fig. 5). Elastatinal, a non-peptide low molecular weight (aldehyde) [41], was used as a specific inhibitor of elastase for control purposes. For elastatinal, a positive correlation was established between its concentration and the inhibition of PPE. For the inhibitors Pep4 and Pep4M a positive correlation could not be unambiguously established in the range of concentrations studied. The highest level of inhibition, circa $40 \%$, was achieved with $1 \mu \mathrm{M}$ and $4 \mu \mathrm{M}$ concentrations of Pep4 and Pep4M, respectively. At $1 \mu \mathrm{M}$ concentration Pep4 is significantly more potent than elastatinal. At $4 \mu \mathrm{M}$ concentration both Pep4 and Pep4M are as potent as elastatinal. The moderate level of inhibition achieved with both peptides suits the objective of the current study. In fact, "complete" inhibition of elastase in wound medium is not required or even recommended. The use of inhibitors aims at restoring the elastase levels, typically found in chronic wounds $(2480.0 \mathrm{ng} / \mathrm{mg}$ protein), to levels similar to those representative of acute healing wounds (245.9 ng/mg protein) $[2,4,15]$.

Phosphorylated cotton wound dressings have been used to sequester excessive protease levels in non-healing chronic wounds, lowering elastase and collagenase activity $40-80 \%$, respectively, comparing to untreated cotton dressings $[10,11]$. The effect of phosphorylation on elastase inhibition was studied for peptides Pep4 and Pep4M. We envisage that a significant difference in inhibition potency between the phosphorylated and non-phosphorylated forms of the inhibitors could be used for tuning elastase activity in the wound environment. In fact, phosphorylated peptides Pep4 and Pep4M at 1 and $4 \mu \mathrm{M}$ concentrations, respectively, are significantly weaker inhibitors than their non-phosphorylated forms (Fig. 4). To exclude the possibility that the decrease observed on elastase inhibition with the phosphorylated peptides could result from some interaction between elastase and CKI/ATP, as the phosphorylation reagents are not separated from the phosphorylated peptides prior testing, elastase activity was measured in the presence of CKI/ATP at the same concentrations as used in the phosphorylation assays. As can be seen (Fig. 4), the elastase activity is virtually unaffected by the phosphorylation reagents. These results emphasize that the decrease of elastase inhibition levels obtained with the phosphorylated peptides, is in fact due to phosphorylation. Phosphorylation of the inhibitor-peptides turns-off their activity. Phosphatase-mediated dephosphorylation could conceivably turnon (restore) their activity.

Thus, the phosphorylation/dephosphorylation process of inhibitor peptides can be conceived as a "kind of" on-off molecular switch, to fine tune the elastase activity in chronic wounds

\subsection{Peptide degradation studies - by mass spectrometry}

In normal wound healing the regeneration of skin tissues is performed by keratinocytes and fibroblasts. Fibroblasts play a crucial role in mediating wound healing responses, ranging from the remodelling of the extracellular matrix (ECM) to the production of grow factors [42]. Degrading processes, like destruction of extracellular matrix and grow factors, prevent wound closure. Therefore, the active materials (inhibitors, moisturiser, antimicrobial, among others) to be delivered by wound dressings to the wound environment, have to be degraded by the wound medium, otherwise they can act as harmful contaminants and compromise other biological processes relevant to wound healing. Hence, degradation studies of the inhibitor peptides and casein kinase I $\delta$ by elastase, were performed in vitro. The ESI mass spectra of Pep4, Pep4M and Elastatinal (data not shown) display main peaks at $m / z$ 1439.92, 1552.06 and 555.6, respectively, in accordance to calculated molecular weights. 
Table 1

Peptide library identification and putative phosphorylation sites for the selected peptides. Peptide phosphorylation site predictions were performed at NetPhos 2.0 server.

\begin{tabular}{|c|c|c|c|c|c|c|c|c|}
\hline $\begin{array}{l}\text { Peptide } \\
\text { number }\end{array}$ & Origin & Protein primary structure & $\begin{array}{l}\text { Protein } \\
\text { fragment }\end{array}$ & Sequence $(\mathrm{N} \rightarrow \mathrm{C})$ & $\begin{array}{l}\text { Targeted } \\
\text { kinase type }\end{array}$ & Reacted kinase & NetPhos prediction ${ }^{\mathrm{a}}$ & $\begin{array}{l}\text { NetPhos } \\
\text { score }\end{array}$ \\
\hline 1 & SLPI & SGKSFKAGVC PPKKSAQCLR & $9-21$ & VCPPKKSAQCLRY & $\mathrm{S}$ & Casein kinase I $\delta$ & - & - \\
\hline 2 & $"$ & YKKPECQSDW QCPGKKRCCP & $22-34$ & KKPECQSDWQCPG & S & " & - & - \\
\hline 3 & " & DTCGIKCLDP VDTPNPTRRK & $94-106$ & MGMCGKSCVSPVK & $\mathrm{S}$ & " & MGMCGKSCVSPVK & 0.680 \\
\hline 4 & " & PGKCPVTYGQ CLMLNPPNFC & $36-48$ & KRCCPDTCGIKCL & $\mathrm{T}$ & " & - & - \\
\hline 5 & $"$ & EMDGQCKRDL KCCMGMCGKS & $47-59$ & CLDPVDTPNPTRR & $\mathrm{T}$ & $"$ & CLDPVDTPNPTRR & 0.991 \\
\hline 6 & " & CVSPVKA & $51-63$ & VDTPNPTRRKPGK & $\mathrm{T}$ & " & VDTPNPTRRKPGK & 0.968 \\
\hline 7 & $"$ & & $61-73$ & PGKCPVTYGQCLM & $\mathrm{T}$ & $"$ & - & - \\
\hline 8 & " & & $15-27$ & SAQCLRYKKPECQ & $\mathrm{S}$ & " & - & - \\
\hline 9 & " & & $62-74$ & GKCPVTYGQCLML & $\mathrm{T}$ & " & - & - \\
\hline 10 & R-Elafin & AQEPVKGPVS TKPGSCPIIL & $4-16$ & PVKGPVSTKPGSC & $\mathrm{S} / \mathrm{T}$ & $"$ & PVKGPVSTKPGSC & 0.991 \\
\hline 11 & " & IRCAMLNPPN RCLKDTDCPG & $9-21$ & VSTKPGSCPIILI & $\mathrm{S} / \mathrm{T}$ & " & - & - \\
\hline 12 & " & IKKCCEGSCG MACFVPQ & $42-54$ & KKCCEGSCGMACF & $\mathrm{S}$ & $"$ & - & - \\
\hline 13 & " & & $5-17$ & VKGPVSTKPGSCP & $\mathrm{S} / \mathrm{T}$ & $"$ & VKGPVSTKPGSCP & 0.991 \\
\hline 14 & $"$ & & $30-42$ & NRCLKDTDCPGIK & $\mathrm{T}$ & $"$ & - & - \\
\hline 15 & ECP & MRPPQFTRAQ WFAIQHISLN & $12-24$ & FAIQHISLNPPRC & S & " & _ & _- \\
\hline 16 & $"$ & PPRCTIAMRA INNYRWRCKN & $54-66$ & NVCGNQSIRCPHN & $\mathrm{S}$ & $"$ & - & - \\
\hline 17 & $"$ & QNTFLRTTFA NVVNVCGNQS & $69-81$ & LNNCHRSRFRVPL & $\mathrm{S}$ & $"$ & - & - \\
\hline 18 & " & IRCPHNRTLN NCHRSRFRVP & 89-101 & PGAQNISNCRYAD & $\mathrm{S}$ & $"$ & PGAQNISNCRYAD & 0.926 \\
\hline 19 & " & LLHCDLINPG AQNISNCRYA & $114-126$ & NRDPRDSPRYPVV & $\mathrm{S}$ & " & NRDPRDSPRYPVV & 0.998 \\
\hline 20 & " & DRPGRRFYVV ACDNRDPRDS & $1-13$ & MRPPQFTRAQWFA & $\mathrm{T}$ & " & - & - \\
\hline 21 & " & PRYPVVPVHL DTTI & $19-31$ & LNPPRCTIAMRAI & $\mathrm{T}$ & $"$ & LNPPRCTIAMRAI & 0.643 \\
\hline 22 & " & & $37-49$ & RCKNQNTFLRTTF & $\mathrm{T}$ & $"$ & - & - \\
\hline 23 & $"$ & & $41-53$ & QNTFLRTTFANVV & $\mathrm{T}$ & $"$ & - & - \\
\hline 24 & " & & $42-54$ & NTFLRTTFANVVN & $\mathrm{T}$ & $"$ & - & - \\
\hline 25 & " & & $62-74$ & RCPHNRTLNNCHR & $\mathrm{T}$ & " & - & - \\
\hline 26 & $"$ & & $28-40$ & MRAINNYRWRCKN & - & $"$ & - & - \\
\hline 27 & " & & $93-105$ & NISNCRYADRPGR & $\mathrm{s}$ & " & NISNCRYADRPGR & 0.958 \\
\hline 28 & " & & $102-114$ & RPGRRFYVVACDN & - & " & - & - \\
\hline 29 & " & & $117-129$ & PRDSPRYPVVPVH & $\mathrm{S}$ & " & PRDSPRYPVVPVH & $0.988 / 0.884$ \\
\hline 30 & SP-D & ASLRQQVEAL QGQVQHLQAA & $16-28$ & HLQAAFSQYKKVE & $\mathrm{S}$ & $"$ & - & - \\
\hline 31 & " & FSQYKKVELF PNGQSVGEKI & $29-41$ & LFPNGQSVGEKIF & $\mathrm{s}$ & $"$ & - & - \\
\hline 32 & " & FKTAGFVKPF TEAQLLCTQA & $60-72$ & AGGQLASPRSAAE & $\mathrm{S}$ & " & AGGQLASPRSAAE & 0.885 \\
\hline 33 & $"$ & GGQLASPRSA AENAALQQLV & $63-75$ & QLASPRSAAENAA & $\mathrm{S}$ & $"$ & QLASPRSAAENAA & 0.835 \\
\hline 34 & " & VAKNEAAFLS MTDSKTEGKF & $84-96$ & NEAAFLSMTDSKT & $\mathrm{S} / \mathrm{T}$ & " & NEAAFLSMTDSKT & 0.974 \\
\hline 35 & " & TYPTGESLVY SNWAPGEPND & $88-100$ & FLSMTDSKTEGKF & $\mathrm{S} / \mathrm{T}$ & " & FLSMTDSKTEGKF & 0.966 \\
\hline 36 & " & DGGSEDCVEI FTNGKWNDRA & $101-113$ & TYPTGESLVYSNW & $\mathrm{S} / \mathrm{T}$ & $"$ & - & - \\
\hline 37 & " & CGEKRLVVCE F & $105-117$ & GESLVYSNWAPGE & $\mathrm{S}$ & $"$ & GESLVYSNWAPGE & 0.771 \\
\hline 38 & " & & $118-130$ & PNDDGGSEDCVEI & $\mathrm{S}$ & $"$ & - & - \\
\hline 39 & " & & $37-49$ & GEKIFKTAGFVKP & $\mathrm{T}$ & $"$ & - & - \\
\hline 40 & " & & $45-57$ & GFVKPFTEAQLLC & $\mathrm{T}$ & $"$ & - & - \\
\hline 41 & " & & $52-64$ & EAQLLCTQAGGQL & $\mathrm{T}$ & " & - & - \\
\hline 42 & $"$ & & $86-98$ & AAFLSMTDSKTEG & $\mathrm{S} / \mathrm{T}$ & $"$ & AAFLSMTDSKTEG & $0.924 / 0.872$ \\
\hline 43 & " & & $90-102$ & SMTDSKTEGKFTY & $\mathrm{S} / \mathrm{T}$ & $"$ & SMTDSKTEGKFTY & $0.516 / 0.971$ \\
\hline 44 & " & & $95-107$ & KTEGKFTYPTGES & $\mathrm{S} / \mathrm{T}$ & $"$ & - & - \\
\hline 45 & " & & $98-110$ & GKFTYPTGESLVY & $\mathrm{S} / \mathrm{T}$ & $"$ & - & - \\
\hline 46 & " & & $126-138$ & DCVEIFTNGKWND & $\mathrm{T}$ & $"$ & - & - \\
\hline 47 & $"$ & & $18-30$ & QAAFSQYKKVELF & S & $"$ & QAAFSQYKKVELF & 0.561 \\
\hline 48 & " & & $96-108$ & TEGKFTYPTGESL & $\mathrm{S}$ & $"$ & - & - \\
\hline 49 & " & & $104-116$ & TGESLVYSNWAPG & $\mathrm{S} / \mathrm{T}$ & $"$ & TGESLVYSNWAPG & 0.771 \\
\hline
\end{tabular}

a The NetPhos 2.0 server [35] produces neural network predictions for serine, threonine and tyrosine phosphorylation sites in eukaryotic proteins. The prediction method can be accessed at http://www.cbs.dtu.dk/services/NetPhos/. The current phosphorylation sites predictions were acquired for a threshold above 0.5 (higher score 1.0 ).

The degradation of inhibitor peptides Pep4, Pep4M and Elastatinal $(0.5 \mathrm{mM})$ by elastase $(0.3$ units $/ \mathrm{mL})$ in a ratio $3: 1(\mathrm{v} / \mathrm{v})$ was studied by MS spectrometry over $120 \mathrm{~min}$ (Table 2 and Fig. 5). In the elastatinal assay, no decrease of the peak at $m / z 555.6$ was observed, confirming that this non-peptide inhibitor is not degraded by elastase during the incubation period of the assay.

The decrease of the area of the peaks at $m / z 1439.92$ and 1552.06, corresponding to intact peptides Pep4 and Pep4M, respectively, suggests enzymatic degradation. It can be concluded that both peptides are degraded by elastase, with Pep4 being much more susceptible to proteolysis than Pep4M. After 60 min of incubation approximately $93 \%$ of Pep4 had been degraded comparing to only $6 \%$ of Pep4M. It is consensually accepted that PPE cleaves peptides predominantly at the C-terminal of hydrophobic amino acids such as Gly, Val, Leu, Ala, Ile, and to lesser extent after Phe, Pro, Glu, and Arg [43,44]. The disappearance of peptides Pep4 and Pep4M correlates with the appearance of fragments at $\mathrm{m} / z 923.66$ and 1179.89 , respectively, putatively assigned to fragments KRCCPDTC

Table 2

MS study on the degradation of Pep4, Pep4M and Elastatinal ( $0.5 \mathrm{mM})$ by PPElastase ( $0.3 \mathrm{units} / \mathrm{mL})$, in a ratio 3:1 (v/v) during an incubation period of 120 min.

\begin{tabular}{|c|c|c|c|c|c|c|c|c|}
\hline \multirow[t]{2}{*}{ Inhibitor } & \multirow[t]{2}{*}{ Structure } & \multicolumn{7}{|c|}{ Incubation period (min) } \\
\hline & & 5 & 15 & 30 & 45 & 60 & 90 & 120 \\
\hline \multicolumn{9}{|c|}{ Relative abundance \pm SD $(\%)$} \\
\hline Pep4 & KRCCPDTCGIKCL & $100 \pm 0$ & $82.1 \pm 5.1$ & $24.3 \pm 7.3$ & $13.2 \pm 3.4$ & $7.3 \pm 2.9$ & $0.9 \pm 1.6$ & 0 \\
\hline Pep4M & KRMMPDTMGIKML & $100 \pm 0$ & $100 \pm 0$ & $100 \pm 0$ & $100 \pm 0$ & $93.6 \pm 3.4$ & $38.6 \pm 8.3$ & 0 \\
\hline Elastatinal & $\mathrm{C} 21 \mathrm{H} 36 \mathrm{~N} 8 \mathrm{O} 7$ & $100 \pm 0$ & $100 \pm 0$ & $100 \pm 0$ & $100 \pm 0$ & $100 \pm 0$ & $100 \pm 0$ & $100 \pm 0$ \\
\hline
\end{tabular}


and KRMMPDTMGI. This is in accordance to a new study that has identified Ala, Val, Ile, Thr, Ser, Leu, and Met as potential cleavage sites for PPElastase [45]. These results might also explain the data obtained for elastase inhibition by these peptides. The degradation of the peptides by elastase means that they are not true inhibitors of the enzyme. They are actually substrates with a slow rate of hydrolysis. Consequently, at low peptide concentrations their hydrolysis rate is very low and therefore they function as inhibitors. However, at higher concentrations the hydrolysis rate increases and their inhibitory effect is decreased.

It is worth noting that the degradation studies in vitro were performed using elastase at higher concentration, 75 munits/mL ( 1 part PPE ( 0.3 units $/ \mathrm{mL}): 3$ parts inhibitor), than that present in wound medium, 36-54 munits/ml [5]. It is, thus, reasonable to assume that the inhibitor peptides might display longer life times in wound exudates, suitable for practical applications in wound dressings. In conclusion, both inhibitor-peptides are degraded by elastase and can be assumed safe for applications as active materials in wound dressings.

\subsection{Casein kinase degradation studies - by mass SDS-PAGE}

Degradation studies of casein kinase I $\delta$ by elastase were performed by SDS-PAGE. Preliminar studies were performed in order to determine the detection limit for CKI and elastase in SDS-PAGE and the optimal assay conditions (data not shown). A mixture of elastase $(0.005$ units $/ \mu \mathrm{L})$ and CKI $(0.2$ units $/ \mu \mathrm{L})$, was incubated for $60 \mathrm{~min}$ at $37^{\circ} \mathrm{C}$. Aliquots were removed from the reaction mixture at different incubation periods and analysed by SDS-PAGE (Fig. 6). After $10 \mathrm{~min}$ the bands corresponding to CKI are not detectable indicating that CKI has been degraded to a level below its detection limit. In contrast, the elastase bands can still be seen even after 60 min of incubation. The elastase-mediated degradation of CKI, as pointed out above for the inhibitor-peptides, indicates that CKI might be safely used also in the formulation of wound dressings.

\section{Conclusions}

In the present study, a library of 13 mer peptides, derived from the primary sequence of the endogenous proteins SLPI, Elafin, ECP and SP-D, was designed. The central position (position 7) of each library member was chosen bearing a phosphor acceptor site. Screening the library in a microarray format identified a robust hit, Pep4, which could be reliably phosphorylated by CKI. This peptide was characterised in solution as a moderate PPE inhibitor. Replacement of the four cysteine residues on Pep4 by methionine residues generated a new peptide (Pep4M), also a good substrate for CKI and a moderate inhibitor of PPE. Both phosphorylated peptides demonstrated to be weaker inhibitors of PPE than their dephosphorylated forms. MS and SDS-PAGE studies demonstrated that both peptides and CKI are degraded by elastase. The use of inhibitors that are degraded by their target enzyme is desirable for safe application in wound dressings. The controlled release of inhibitor-peptides coupled to degradation by the target protease can be seen as a biomimetic safe approach for controlling protease burden in chronic wounds. Moreover, differential inhibition by the phosphorylated and dephosphorylated forms of the peptides could allow fine tuning the elastase inhibition process. It is important to stress that this is a model system, intended as proof-of-concept. In this context, CKI was selected as a model (available) enzyme, not present, as far as we know, on wound exudates. Our research group has described recently elastase-mediated controlled-release of inhibitor peptides from degradable biomatrices composed of silk fibroin and keratin $[46,47]$. This system could conceptually be extended to combine a first layer containing the inhibitor-peptide and a second layer containing the protein kinase. Practical implementation of the concept devised in this study will require deep knowledge about the composition of wound exudates and extensive optimisation of biomatrices, inhibitor-peptides and kinase degradation rates and loadings.

\section{Acknowledgements}

This work was supported by the European Project Lidwine Multifunctional medical textiles for wound (e.g. Decubitus) prevention and improved wound healing. S.C.B. is supported by grants from the Lidwine Project and Foundation for Science and Technology (SFRH/BD/36522/2007). The results divulgation were supported by the COST Action 868. The authors are grateful to Professor Manuel dos Santos and Doutora Laura Carreto (Biology Department, Aveiro University) for use of the DNA microarray readers.

\section{References}

[1] Braund R, Hook S, Medlicott NJ. The role of topical growth factors in chronic wounds. Current Drug Delivery 2007;4:195-204.

[2] Schonfelder U, Abel M, Wiegand C, Klemm D, Elsner P, Hipler UC. Influence of selected wound dressings on PMN elastase in chronic wound fluid and their antioxidative potential in vitro. Biomaterials 2005;26:6664-73.

[3] Yager DR, Chen SM, Ward SI, Olutoye OO, Diegelmann RF, Kelman Cohen I. Ability of chronic wound fluids to degrade peptide growth factors is associated with increased levels of elastase activity and diminished levels of proteinase inhibitors. Wound Repair and Regeneration 1997;5:23-32.

[4] Wiegand C, Schönfelder U, Abel M, Ruth P, Kaatz M, Hipler U-C. Protease and pro-inflammatory cytokine concentrations are elevated in chronic compared to acute wounds and can be modulated by collagen type I in vitro. Archives of Dermatological Research 2010;302:419-28.

[5] Edwards JV, Howley P, Cohen IK. In vitro inhibition of human neutrophil elastase by oleic acid albumin formulations from derivatized cotton wound dressings. International Journal of Pharmaceutics 2004;284:1-12.

[6] Fitch PM, Roghanian A, Howie SEM, Sallenave JM. Human neutrophil elastase inhibitors in innate and adaptive immunity. Biochemical Society Transactions 2006;34:279-82.

[7] Edwards JV, Bopp A, Yachmenev V, Goheen S, Yager D, Cohen I. Research and development of an active cotton-based wound dressing for use in chronic wounds. In: Beltwide Cotton Textile Processing Conference Proceedings. 2004. p. 2851-5.

[8] Vincent EJ, Alvin FB, Sarah B, Abul JU, Kelman CI, Robert FD, et al. Inhibition of elastase by a synthetic cotton-bound serine protease inhibitor: in vitro kinetics and inhibitor release. Wound Repair and Regeneration 1999;7:106-18.

[9] Edwards JV, Eggleston G, Yager DR, Cohen IK, Diegelmann RF, Bopp AF. Design, preparation and assessment of citrate-linked monosaccharide cellulose conjugates with elastase-lowering activity. Carbohydrate Polymers 2002;50:305-14.

[10] Edwards JV, Yager DR, Cohen IK, Diegelmann RF, Montante S, Bertoniere N, et al. Modified cotton gauze dressings that selectively absorb neutrophil elastase activity in solution. Wound Repair and Regeneration 2001;9:50-8.

[11] Edwards JV, Phyllis SH. Human neutrophil elastase and collagenase sequestration with phosphorylated cotton wound dressings. Journal of Biomedical Materials Research Part A 2007;83A:446-54.

[12] Annie J, David V. Hydrogel dressings in the management of a variety of wound types: a review. Journal of Orthopaedic Nursing 2005;9:S1-11.

[13] Weller C, Sussman G. Wound dressings update. Journal of Pharmacy Practice and Research 2006;36:318-24.

[14] Ovington LG. Advances in wound dressings. Clinics in Dermatology 2007;25:33-8.

[15] Edwards VB-D, Gisela, Goheen S, editors. Modified fibers with medical and specialty applications. Dordrecht: Springer; 2006.

[16] Edwards JV, Howley P, Davis R, Mashchak A, Goheen SC. Protease inhibition by oleic acid transfer from chronic wound dressings to albumin. International Journal of Pharmaceutics 2007;340:42-51.

[17] Francart C, Dauchez M, Alix AJP, Lippens G. Solution structure of r-elafin, a specific inhibitor of elastase. Journal of Molecular Biology 1997;268:666-77.

[18] Tsunemi M, Kato H, Nishiuchi Y, Kumagaye S-i, Sakakibara S. Synthesis and structure-activity relationships of elafin, an elastase-specific inhibitor. Biochemical and Biophysical Research Communications 1992;185:967-73.

[19] Tsunemi M, Matsuura Y, Sakakibara S, Katsube Y. Crystal structure of an elastase-specific inhibitor elafin complexed with porcine pancreatic elastase determined at 1.9 ̊ resolution. Biochemistry 1996;35:11570-6.

[20] Koizumi M, Fujino A, Fukushima K, Kamimura T, Takimoto-Kamimura M. Complex of human neutrophil elastase with 1/2SLPI. Journal of Synchrotron Radiation 2008;15:308-11

[21] Moreau T, Baranger K, Dadé S, Dallet-Choisy S, Guyot N, Zani M-L. Multifaceted roles of human elafin and secretory leukocyte proteinase inhibitor 
(SLPI), two serine protease inhibitors of the chelonianin family. Biochimie 2008;90:284-95

[22] Li Z, Moy A, Sohal K, Dam C, Kuo P, Whittaker J, et al. Expression and characterization of recombinant human secretory leukocyte protease inhibito (SLPI) protein from Pichia pastoris. Protein Expression and Purification 2009;67:175-81.

[23] Venge P, Byström J. Molecules in focus Eosinophil cationic protein (ECP). The International Journal of Biochemistry \& Cell Biology 1998;30:433-7.

[24] Mohan CG, Boix E, Evans HR, Nikolovski Z, Nogues MV, Cuchillo CM, et al. The crystal structure of Eosinophil cationic protein in complex with $2^{\prime}, 5^{\prime}-\mathrm{ADP}$ at $2.0 \AA$ resolution reveals the details of the ribonucleolytic active site. Biochemistry 2002; $41: 12100-6$.

[25] Boix E, Nikolovski Z, Moiseyev GP, Rosenberg HF, Cuchillo CM, Nogues MV. Kinetic and product distribution analysis of human eosinophil cationic protein indicates a subsite arrangement that favors exonuclease-type activity. Journal of Biological Chemistry 1999;274:15605-14.

[26] Carreras E, Boix E, Rosenberg HF, Cuchillo CM, Nogues MV. Both aromatic and cationic residues contribute to the membrane-lytic and bactericidal activity of eosinophil cationic protein. Biochemistry 2003;42:6636-44

[27] Temkin V, Aingorn H, Puxeddu I, Goldshmidt O, Zcharia E, Gleich GJ, et al. Eosinophil major basic protein: first identified natural heparanase-inhibiting protein. Journal of Allergy and Clinical Immunology 2004;113:703-9.

[28] Persson A, Rust K, Chang D, Moxley M, Longmore W, Crouch E. Cp4 - a pneumocyte-derived collagenous surfactant-associated protein - evidence for heterogeneity of collagenous surfactant proteins. Biochemistry 1988;27:8576-84.

[29] Haczku A. Protective role of the lung collectins surfactant protein A and surfactant protein D in airway inflammation. Journal of Allergy and Clinical Immunology 2008;122:861-79.

[30] Kankavi O, Ata A, Celik-Ozenci C, Sati L, Ciftcioglu MA, Demir R, et al. Presence and subcellular localizations of surfactant proteins A and D in human spermatozoa. Fertility and Sterility 2008;90:1904-9.

[31] Kishore U, Greenhough TJ, Waters P, Shrive AK, Ghai R, Kamran MF, et al. Surfactant proteins SP-A and SP-D: structure, function and receptors. Molecular Immunology 2006;43:1293-315.

[32] Holger W, Rudolf V-E, Margit S, Marco S, Jens S-M, Ulrich R. Coherent membrane supports for parallel microsynthesis and screening of bioactive peptides. Peptide Science 2000;55:188-206.

[33] Bieth J, Spiess B, Wermuth CG. Synthesis and analytical use of a highly sensitive and convenient substrate of elastase. Biochemical Medicine 1974;11:350-7.

[34] Laemmli UK. Cleavage of structural proteins during assembly of head of bacteriophage-T4. Nature 1970;227:680-5.
[35] Blom N, Gammeltoft S, Brunak S. Sequence and structure-based prediction of eukaryotic protein phosphorylation sites. Journal of Molecular Biology 1999;294:1351-62.

[36] Flotow H, Graves PR, Wang AQ Fiol CJ, Roeske RW, Roach PJ. Phosphate groups as substrate determinants for casein kinase I action. Journal of Biological Chemistry 1990;265:14264-9.

[37] Oriano M, Flavio M, Stefania S, Monica A, Lorenzo AP. Phosphorylation of synthetic fragments of inhibitor- 2 of protein phosphatase- 1 by casein kinase- 1 and -2. European Journal of Biochemistry 1994;223:647-53.

[38] Meggio F, Perich JW, Reynolds EC, Pinna LA. A synthetic [beta]-casein phosphopeptide and analogues as model substrates for casein kinase- 1 , a ubiquitous, phosphate directed protein kinase. FEBS Letters 1991;283:303-6.

[39] Koresawa M, Okabe T. High-throughput screening with quantitation of ATP consumption: a universal non-radioisotope, homogeneous assay for protein kinase. Assay and Drug Development Technologies 2004;2: 153-60.

[40] Kupcho K, Somberg R, Bulleit B, Goueli SA. A homogeneous, nonradioactive high-throughput fluorogenic protein kinase assay. Analytical Biochemistry 2003:317:210-7.

[41] Umezawa H, Aoyagi T, Okura A, Morishim H, Takeuchi T, Okami Y. Elastatinal a new elastase inhibitor produced by actinomycetes. Journal of Antibiotics 1973;26:787-9.

[42] Cook H, Stephens P, Davies KJ, Harding KG, Thomas DW. Defective extracellular matrix reorganization by chronic wound fibroblasts is associated with alterations in TIMP-1, TIMP-2, and MMP-2 activity. Journal of Investigative Dermatology 2000;115:225-33.

[43] Getie M, Schmelzer CEH, Neubert RHH. Characterization of peptides resulting from digestion of human skin elastin with elastase. Proteins: Structure, Function, and Bioinformatics 2005;61:649-57.

[44] Mecham RP, Broekelmann TJ, Fliszar CJ, Shapiro SD, Welgus HG, Senior RM. Elastin degradation by matrix metalloproteinases. Journal of Biological Chemistry 1997;272:18071-6.

[45] Wang B, Malik R, Nigg EA, Korner R. Evaluation of the low-specificity protease elastase for large-scale phosphoproteome analysis. Analytical Chemistry 2008;80:9526-33.

[46] Vasconcelos A, Barros S, Cavaco-Paulo A. Switch on-switch off system for the inhibition of elastase on wound exudates. In: Proceedings 6th International Conference on Textile and Polymer Biotechnology. 2009. p. $273-4$.

[47] Vasconcelos A, Pêgo AP, Henriques L, Lamghari M, Cavaco-Paulo A. Protein matrices for improved wound healing: elastase inhibition by a synthetic peptide model. Biomacromolecules 2010;11:2213-20. 